\title{
Postoperative retention of urine: a prospective urodynamic study
}

\author{
J B Anderson, J B F Grant
}

\begin{abstract}
Objective-To investigate the cause of postoperative retention of urine in elderly men.

Design-Prospective study.

Setting-Northern General Hospital, Sheffield.

Patients -32 consecutive men (median age 73, range 55-85) referred to the urology department who were unable to pass urine either within 48 hours after operation and required catheterisation (23) or after removal of a catheter inserted at the initial operation (nine).
\end{abstract}

Intervention-Intermittent self catheterisation.

Main outcome measures-Urological investigation by medium fill and voiding cystometry within four weeks after operation, and minimum follow up three months thereafter.

Results-6 patients resumed normal voiding before urodynamic assessment, three proceeded straight to prostatectomy, and one was unfit for self catheterisation. Of 22 men who underwent urodynamic investigation, only five had bladder outflow obstruction, who subsequently had successful prostatectomy; 15 showed either a low pressure-low flow system (seven) or complete detrusor failure (eight) and two showed pelvic parasympathetic nerve damage. With intermittent self catheterisation spontaneous voiding returned in all but one man within a median of 8 weeks (range 6-32 weeks). Recovery of bladder function took significantly longer in men with detrusor failure than in those with an underactive bladder (median 10 weeks (range 6-32 weeks) $v$ median 8 weeks (range 6-8 weeks); $p=0 \cdot 05$ ). Three months later all patients had re-established their own normal voiding pattern with minimal residual urine on ultrasonography and satisfactory flow rates.

Conclusions-Postoperative urinary retention in elderly men is not an indication for prostatectomy; a normal pattern of micturition can be re-established by intermittent self catheterisation in most men.

\section{Introduction}

Postoperative retention of urine is a common and troublesome complication of any surgical procedure. The incidence is reported to be as high as $32 \%$ after surgery for benign anorectal disease, ${ }^{1} 23 \%$ after laparotomy, ${ }^{2} 28 \%$ after total hip arthroplasty, ${ }^{3}$ and $12 \%$ after inguinal herniorrhaphy in men aged over 50 years. ${ }^{+}$ Symptoms of bladder outflow obstruction due to an enlarged prostate gland are also common, and a 40 year old man has up to a $29 \%$ chance of requiring a prostatectomy if he lives to be $80 .^{5}$ Retention of urine may be the first manifestation of prostatic disease in up to $40 \%$ of cases."

There is therefore a dilemma when treating an elderly man who is experiencing difficulties with micturition in the postoperative period, who not uncommonly admits to a varying degree of preoperative urinary symptoms. Once he has failed his trial without a catheter it is commonly assumed that his urinary problems are obstructive in nature, and he is sentenced to prostatectomy. Such a view is encouraged in standard surgical texts. ${ }^{78}$

We have been impressed by the painless nature of the retention and the large residual volume of urine drained after catheterisation in most of these patients. Rather than the retention being precipitated by outflow obstruction due to prostatic hyperplasia, the underlying disorder may be in bladder function. To investigate this possibility we carried out a prospective study of a consecutive series of patients who were unable to pass urine after various surgical procedures.

\section{Patients and methods}

We studied 32 men with a median age of 73 years (range 55 to 83 years). Twenty three developed urinary retention within 48 hours after surgery and were catheterised for a median of two days (range 15 minutes to 16 days). We defined retention as the inability to pass urine for at least 12 hours after operation with more than $500 \mathrm{ml}$ of urine drained on catheterisation. In the remaining nine men a catheter had been inserted at the time of the initial operation and was removed at a median of five days (range two to eight days).

Table I lists the types of surgical procedure carried out on these men, together with the number of men catheterised at the time of operation and the overall duration of catheterisation. All men had been given a general anaesthetic, and 27 were paralysed and intubated, requiring subsequent reversal of neuromuscular blockade by neostigmine and atropine. Twenty six were given parenteral opiates for postoperative analgesia, with a further two receiving fentanyl through an epidural catheter.

TABLE I-Retention of urine in 32 men after different types of operation

\begin{tabular}{lccl}
\hline Type of operation & $\begin{array}{c}\text { No of } \\
\text { men }\end{array}$ & $\begin{array}{c}\text { No catheterised } \\
\text { peroperatively }\end{array}$ & $\begin{array}{c}\text { Median duration } \\
\text { (range) of } \\
\text { catheterisation (days) }\end{array}$ \\
\hline Abdominal & 11 & 4 & 4 days (1-8 days) \\
Inguinal or perineal & 3 & 0 & 1 day (30 min-2 days) \\
Cardiothoracic & 9 & 5 & 3 days (30 min-8 days) \\
Hip or knee & 9 & 0 & 1 day (30 min-3 days) \\
\hline
\end{tabular}

After removal of the catheter failure to void resulted in referral to the urology department and inclusion in this study. The men were started on clean intermittent self catheterisation with a 12 French gauge Nelaton catheter, initially at intervals of six hours. Urodynamic assessment was arranged within four weeks after their original operation. This comprised medium fill cystometry $(50 \mathrm{ml} / \mathrm{min}$ at ambient temperature) through a transurethral 10 French gauge Portex intravenous long line with the patient supine. Total bladder pressure was measured by means of a 4 French gauge infant feeding tube passed into the bladder with the filling catheter and abdominal pressure by means of a water filled rectal catheter. Detrusor pressure was obtained by electronic subtraction, and all pressures were displayed on a Disa recorder. Pressures are in centimetres of water and are referred to zero pressure at the level of the uper border of the symphysis pubis. At capacity the patient was tilted into the erect position and requested to void with the lines in situ.

All methods and terminology conform to the recommendations of the International Continence Society Committee." The data are reported as medians and
Department of Urology, Sheffield S10 2JF. 
ranges, and non-parametric statistical analysis was performed with the Mann-Whitney U test.

\section{Results}

Sixteen of the 32 men admitted to urinary hesitancy or a poor stream before operation. In only six was the postoperative retention of urine associated with suprapubic pain. Three passed urine satisfactorily after a second trial without a catheter (table II), and a further three resumed normal voiding before urodynamic assessment and therefore discontinued intermittent self catheterisation. No further investigation or treatment was thought to be justified in these men; all were subsequently reviewed at three months and maintained their normal voiding pattern with minimal residual volumes on ultrasonography and satisfactory flow rates. As a result of pressure from the referring surgeons transurethral prostatectomy was performed on three patients, all with artificial heart valves, because of a theoretical risk of infection resulting from self catheterisation. These patients did not undergo urodynamic assessment, but all obtained a satisfactory result from their operation as judged by postoperative flow rates.

The remaining 22 men were all submitted to urodynamic investigation at 21 days ( 9 to 30 days) after their initial operation. Table III summarises the results.

Five patients were found to have bladder outflow obstruction with a maximum subtracted detrusor pressure rise $>80 \mathrm{~cm} \mathrm{H}_{2} \mathrm{O}$ and a maximum flow rate $<5 \mathrm{ml} / \mathrm{s}$. The initial residual urinary volume after catheterisation in this group was $550 \mathrm{ml}(500$ to $650 \mathrm{ml}$ ). All five patients subsequently underwent transurethral prostatectomy and voided with good flow rates when reviewed in clinic at three months.

Two patients who had each undergone abdominoperineal excision of the rectum for a Dukes $\mathrm{C}$ carcinoma showed the characteristic urodynamic features of pelvic parasympathetic nerve damage with detrusor hypocompliance, lack of voluntary detrusor activity, and an open bladder neck on screening during the bladder filling phase. One patient had to perform intermittent self catheterisation every five to six hours to maintain continence whereas the other was continent and able to empty his bladder almost to completion by abdominal straining.

The 15 other patients showed either a low pressurelow flow system with a maximum subtracted detrusor pressure rise of $40 \mathrm{~cm} \mathrm{H} \mathrm{H}_{2} \mathrm{O}$ and a flow rate of $10 \mathrm{ml} / \mathrm{s}$ (seven) or an acontractile detrusor muscle with voiding only by abdominal straining (eight). Overall, nine of these patients had previous slowing of the urinary stream or hesitancy, but none had developed painful retention after their original surgery. The initial

TABLE II-Outcome in 10 men not undergoing urodynamic investigation

\begin{tabular}{lr}
\hline & No \\
\hline Passed second trial without catheter & 3 \\
Resumed normal voiding before urodynamic investigation & 3 \\
Unfit for intermittent self catheterisation or further surgery & 1 \\
Transurethral prostatectomy at request of referring surgeons & 3 \\
\hline
\end{tabular}

TABLE III - Urodynamic findings in 22 men with postoperative urinary retention

\begin{tabular}{|c|c|c|c|c|c|}
\hline Urodynamic diagnosis & $\begin{array}{l}\text { No of } \\
\text { men }\end{array}$ & $\begin{array}{c}\text { Median (range) } \\
\text { age (years) }\end{array}$ & $\begin{array}{l}\text { Previous } \\
\text { urinary } \\
\text { symptoms }\end{array}$ & $\begin{array}{l}\text { Painful } \\
\text { postoperative } \\
\text { retention }\end{array}$ & $\begin{array}{c}\text { Median (range) } \\
\text { initial residual } \\
\text { urinary } \\
\text { volume }(\mathrm{ml})\end{array}$ \\
\hline Obstruction & 5 & $76(62-83)$ & 3 & 3 & $550(500-650)$ \\
\hline Post abdominoperineal resection & 2 & 55,57 & 0 & 0 & 600,1000 \\
\hline Low pressure-low flow & 7 & $73(68-81)$ & 5 & 0 & $1000(800-1250)$ \\
\hline Acontractile detrusor & 8 & $75(68-80)$ & 4 & 0 & $1000(500-2000)$ \\
\hline
\end{tabular}

residual urinary volume in these men was significantly greater than that in those with urodynamically proved bladder outflow obstruction $(1000 \mathrm{ml}(500$ to $2000 \mathrm{ml})$ $v 550 \mathrm{ml}(500-650 \mathrm{ml}) ; \mathrm{p}=0.0025)$.

Fourteen of these 15 patients were taught intermittent self catheterisation without difficulty. In all but one spontaneous voiding returned, and they were able to discontinue self catheterisation within 8 weeks (6-32 weeks). Recovery of bladder function took significantly longer in those with detrusor failure compared with those with an underactive bladder ( 10 weeks $(6-32$ weeks) $v 8$ weeks $(6-8$ weeks); $\mathrm{p}=0 \cdot 05)$. With a minimum follow up of three months all men maintained their normal voiding pattern and had negligible residual urinary volumes on ultrasonography. In one man who had still not resumed normal micturition after seven months repeat urodynamic studies showed not only good recovery of detrusor function but appreciable bladder outflow obstruction. After prostatectomy he subsequently also voided satisfactorily.

Among the nine men who had had a catheter inserted in the perioperative period, only one had shown complete detrusor failure on urodynamic testing and his catheter had been removed just 24 hours after aortic valve replacement. He subsequently developed painless urinary retention and had $1200 \mathrm{ml}$ of urine drained on subsequent catheterisation. Two further men within this group developed painless retention of urine when their catheters were removed, in each case after seven days, and urodynamic investigations showed a low pressure-low flow pattern of voiding in both. Of the seven others with problems despite perioperative catheterisation, two had undergone abdominoperineal excision of the rectum, two had obstruction, and two did not undergo urodynamic investigation.

\section{Discussion}

It is often assumed that patients who develop postoperative urinary retention have bladder outflow obstruction ${ }^{70}$ and would therefore benefit from prostatectomy. This study shows that only $23 \%$ of men who failed their initial trial without a catheter had urodynamic obstruction. When men who re-established normal voiding before urodynamic assessment could be performed are included the percentage drops to $18 \%$, which is similar to the overall incidence of bladder outflow obstruction due to benign prostatic hyperplasia. Although there is no reason to assume that men who have an operation are more likely to have prostatic problems, it seems that the number of prostatectomies carried out for postoperative retention of urine exceeds the known incidence of the condition.

Why should so many men experience difficulty with micturition after non-urological surgery? Theories abound, ranging from "vegetative imbalance" the psychological make up of the patient ${ }^{10}$ to the more obvious effects of the operation, general anaesthesia, and postoperative care. After operation a man has several practical difficulties to overcome before he is able to empty his bladder. $\mathrm{He}$ is often immobilised by intravenous lines, nasogastric tubes, and other equipment; he is not accustomed to passing urine lying or sitting in bed; and he is not helped by the lack of privacy in hospital. When he attempts to micturate, pain, especially lower abdominal or perineal pain, hinders perineal relaxation, normally the first step towards initiation of the micturition reflex. Finally, rapid intravenous fluid infusion during and immediately after operation may overfill the bladder, thereby compounding the problem. ${ }^{112}$

While the general effects of anaesthesia and any further sedation will certainly dull the perception of 
bladder fullness in the postoperative period specific drugs given during the course of the operation will also affect the micturition reflex. The smooth muscle of the bladder and urethra contains cholinergic receptors, and anticholinergic agents such as atropine can therefore depress detrusor contraction. As atropine has a plasma half life of up to four hours or longer in elderly patients ${ }^{13}$ detrusor contractility will be impaired over this period. Nine of the 23 patients in this study who were prescribed premedication were given atropine whereas 27 patients paralysed and ventilated at operation had neuromuscular blockade reversed with neostigmine and an anticholinergic agent. With the short duration of action of these agents we cannot be certain that they were responsible for the difficulties with micturition postoperatively but they may well have some part to play in the initial phase of overdistension of the bladder.

Several studies have speculated on the importance of the sympathetic nervous system in the aetiology of postoperative retention of urine. ${ }^{14} 15$ The smooth muscle of the bladder neck and proximal urethra is rich in $\alpha$ adrenergic receptors, ${ }^{16}$ and the normal stress induced sympathetic activity which accompanies surgery may well result in increased bladder outflow resistance.

The final important factor is the use of systemic opiate analgesia. When a patient is given sufficient morphine to relieve postoperative pain not only is the signal to micturate from an overfilled bladder suppressed $^{217}$ but there are also complex effects on peripheral and central neurogenic mechanisms controlling the micturition reflex. ${ }^{18}{ }^{19}$ Experimental animal studies have shown that opiates exert their effects on these reflexes in three ways. (1) Afferent input from the bladder is impaired owing to the activation of opioid receptors on primary afferent nerve terminals. ${ }^{19}$ (2) Opiates depress the preganglionic neurones in the sacral parasympathetic nucleus, resulting in reduced activity in the pelvic nerves. ${ }^{2021}$ (3) Opiates may cause detrusor-sphincter dysnergia due to a failure of sphincter relaxation.2?

Intramuscular papaveretum appreciably decreases the mean intravesical pressure during cystometry ${ }^{23}$ whereas the potent opiate antagonist naloxone causes a rise in the detrusor pressure throughout bladder filling and a reduced bladder capacity at both first and urgent desire to micturate. ${ }^{2+26}$ Twenty six men $(82 \%)$ in our study received regular systemic opiates for several days after their operation, and a further two were given fentanyl through an epidural catheter. These agents seem more likely to have precipitated urinary retention than the shorter acting anticholinergic agents.

In summary, most men who develop difficulties with micturition after surgery do not have obstruction; their problem is one of temporary bladder dysfunction probably due to impaired bladder sensation or reduced detrusor contractility, or both. During and after an operation the detrusor muscle, sphincters, and associated nerves are assaulted by a battery of pharmacological agents all known to affect bladder function. The patient is confined to bed, and any cortical desire to void is dulled by postoperative analgesia. The bladder distends beyond its normal physiological limits, and, in a manner analogous to Starling's law of the heart, the detrusor muscle eventually becomes decompensated. Its elastic properties and the normal voiding reflexes are then lost for a varying period. This study shows that once the pharmacological assault has subsided and the bladder has been drained either by intermittent self catheterisation or by an indwelling catheter the detrusor muscle can be expected to recover its normal function and the patient expected to reestablish his own normal voiding pattern.
1 Petros JG, Bradley TM. Factors influencing postoperative urinary retention in patients undergoing surgery for benign anorectal disease. Am I Surg 1990;159:374-6

2 Stallard S, Prescott S. Postoperative urinary retention in general surgical patients. Br F Surg 1988;75:1141-3.

3 Walts LF, Kaufman RD, Moreland JR, et al. Total hip arthroplasty. Clin Orthop 1985;194:280-2.

4 Haskell DI, Sunshine B, Heifetz CJ. A study of bladder catheterisation with inguinal hernia operations. Arch Surg 1974;109:378-80.

5 Glynn RJ, Campion EW, Bouchard GR, Silbert JE. The development of benign prostatic hyperplasia among volunteers in the normative aging study. Am f Epidemiol 1985:121:78-90.

6 Craigen AA, Hickling JB, Saunders CRG, et al. Natural history of prostatic obstruction: a prospective survey. $\mathcal{F}$ R Coll Gen Pract 1969;18:226-32

7 Mitchell JP. Retention of urine. In: Dudley HAF, ed. Hamilton Bailey's emergency surgery. 11th ed. Bristol: Wright, 1986:507.

8 Ellis H, Calne RY. The prostate. In: Lecture notes on general surgery. 7 th ed. Oxford: Blackwell, 1987:362.

9 International Continence Societv Committee. The standardization of terminology of lower urinary tract function. Br J Obstet Gynaecol 1990;97 (Suppl 6).

10 Tammela T, Kontturi M, Lukkarinen O. Postoperative urinary retention. 1. Incidence and predisposing factors. Scand $\mathcal{F}$ Urol Nephrol 1986;20:197-201.

11 Treiger P, Tovarek JJ, Casciato NA. Physiopsychologic treatment for postoperative urinary retention. Am f Surg 1950;80:195-7.

12 Campbell ED. Prevention of urinary retention after anorectal operations. Dis Colon Rectum 1972;15:69-70.

13 Virtanen R, Kanto J, Lisalo E, et al. Pharmacokinetic studies on atropine with special reference to age. Acta Anaesthesiol Scand 1982;26:297-300.

14 Leventhal A, Pfau A. Pharmacologic management of postoperative overdistension of the bladder. Surg Gynecol Obstet 1978;146:347-8.

15 Marshall V, Ludbrook J. The urinary tract. In: Clinical science for surgeons. 2nd ed. London: Butterworth, 1988:552.

16 Gosling JA, Dixon JS, Lendon RG. The autonomic innervation of the human male and female bladder neck and proximal urethra. $\mathcal{F}$ Urol 1977;118:302-5.

17 Hodsman NBA, Kenney GNC, McArdle CS. Patient controlled analgesia and urinary retention. Br f Surg 1988:75:212.

18 Petersen TK, Husted SE, Rybro L, et al. Urinary retention during IM and extradural morphine analgesia. Brf Anaesth 1982;54:1175-7.

19 Dray A. Epidural opiates and urinary retention: new models provide new insights. Anesthesiology 1988;68:323-4.

20 Dray A, Metsch R. Inhibition of urinary bladder contractions by a spinal action of morphine and other opioids. F Pharmacol Exp Ther 1984;231: 254-60.

21 Hisamitsu T, de Groat WC. The inhibitory effect of opioid peptides and morphine applied intrathecally and intracerebroventricularly on the micturition reflex in the cat. Brain Res 1984;289:51-6.

22 Durant PAC, Yaksh TL. Drug effects on urinary bladder tone during spinal morphine induced inhibition of the micturition reflex in unanesthetised rats. Anesthesiology 1988;68:325-34

23 Doyle P'T, Briscoe CE. The effects of drugs and anaesthetic agents on the urinary bladder and sphincter. Br F Lrol 1976;48:329-35.

24 Vaidyanathan S, Rao MS, Chary KSN, et al. Enhancement of detrusor reflex activity by naloxone in patients with chronic neurogenic bladder dysfunction. $\mathcal{F}$ Urol 1981;126:500-2.

25 Murray KHA, Feneley RCL. Endorphins - a role in lower urinary tract function? The effect of opioid blockade on the detrusor and urethral sphincter mechanisms. Brf Urol 1982;54:638-40.

26 Sandyk R, Gillman MA. Naloxone causes urinary urgency. Crology 1986; $27: 79$.

(Accepted 6 February 1991)

Update box for Oxford Handbook of Clinical Medicine (2nd ed), p 645

\section{Treatment of symptomatic}

\section{hypercalcaemia associated with cancer}

Biphosphonates have replaced calcitonin and plicamycin (also known as mithramycin) as the treatment of choice for severe symptomatic hypercalcaemia associated with cancer. The reason for this is that they work better, ${ }^{\prime}$ and a single dose, lasting up to two months, may be all that is required. ${ }^{2}$ They work by inhibiting bone resorption. Disodium pamidronate is the most widely used. A suitable dose to try is $30 \mathrm{mg}$ by intravenous infusion in $250 \mathrm{ml}$ of $0.9 \%$ saline given over four hours. Fever is a side effect of treatment. To reduce the chances of renal impairment do not start treatment until the patient is well hydrated. - J M LONGMORE

\section{Principal sources}

1 Ralston SH, Gallacher SJ, Patel U, et al. Comparison of three biphosphonates in cancer-associated hypercalcaemia. Lancet 1989;ii:1180-2. Treating cancer-associated hypercalcaemia. Drug Ther Bull 1990;28: 85-7.

Anyone may submit an update box; all boxes are peer reviewed. 